\title{
The metabolic syndrome and renal function in an African cohort infected with human immunodeficiency virus
}

\begin{tabular}{|c|c|}
\hline \multicolumn{2}{|c|}{$\begin{array}{l}\text { Authors: } \\
\text { Edith Phalane }^{1} \text { (D) } \\
\text { Carla M.T. Fourie }^{1,2} \\
\text { Aletta E. Schutte }^{1,2} \text { (D) }\end{array}$} \\
\hline \multicolumn{2}{|c|}{$\begin{array}{l}\text { Affiliations: } \\
{ }^{1} \text { Hypertension in Africa } \\
\text { Research Team, North-West } \\
\text { University, South Africa }\end{array}$} \\
\hline \multicolumn{2}{|c|}{$\begin{array}{l}{ }^{2} \text { Medical Research Council } \\
\text { Unit for Hypertension and } \\
\text { Cardiovascular Disease, } \\
\text { Faculty of Health Sciences, } \\
\text { North-West University, } \\
\text { South Africa }\end{array}$} \\
\hline \multicolumn{2}{|c|}{$\begin{array}{l}\text { Corresponding author: } \\
\text { Carla Fourie, } \\
\text { carla.fourie@nwu.ac.za }\end{array}$} \\
\hline \multicolumn{2}{|c|}{$\begin{array}{l}\text { Dates: } \\
\text { Received: } 01 \text { Nov. } 2017 \\
\text { Accepted: } 29 \text { Mar. } 2018 \\
\text { Published: } 20 \text { Sept. } 2018\end{array}$} \\
\hline \multicolumn{2}{|c|}{$\begin{array}{l}\text { How to cite this article: } \\
\text { Phalane E, Fourie CMT, Schutte } \\
\text { AE. The metabolic syndrome } \\
\text { and renal function in an } \\
\text { African cohort infected with } \\
\text { human immunodeficiency } \\
\text { virus. S Afr J HIV Med. 2018; } \\
\text { 19(1), a813. https://doi.org/ } \\
\text { 10.4102/sajhivmed.v19i1.813 }\end{array}$} \\
\hline \multicolumn{2}{|c|}{$\begin{array}{l}\text { Copyright: } \\
\text { (c) 2018. The Authors } \\
\text { Licensee: AOSIS. This } \\
\text { is licensed under the } \\
\text { Creative Commons } \\
\text { Attribution License. }\end{array}$} \\
\hline \multicolumn{2}{|l|}{ Read online: } \\
\hline 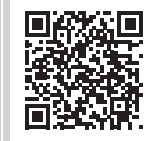 & $\begin{array}{l}\text { Scan this QR } \\
\text { code with your } \\
\text { smart phone or } \\
\text { mobile device } \\
\text { to read online. }\end{array}$ \\
\hline
\end{tabular}

Introduction: The human immunodeficiency virus (HIV) is often accompanied by renal dysfunction. It is expected that metabolic syndrome (MetS) may exacerbate renal impairment.

Objective: We therefore determined the prevalence of MetS and the association thereof with renal function in a South African cohort infected with HIV.

Methods: We matched $114 \mathrm{HIV}$-infected $(77.3 \%$ on antiretroviral therapy [ART] and 22.7\% ART-naïve) and $114 \mathrm{HIV-uninfected} \mathrm{individuals} \mathrm{according} \mathrm{to} \mathrm{age,} \mathrm{sex} \mathrm{and} \mathrm{locality.} \mathrm{We}$ examined cardiovascular, anthropometric and metabolic measurements and determined the MetS. Renal function was assessed using standardised procedures.

Results: The prevalence of MetS was lower in the HIV-infected individuals as compared to the uninfected individuals $(28 \%$ vs. $44 \%, p=0.013)$. The HIV-infected group presented with a lower body mass index (BMI) and waist circumference (WC) (all $p<0.001)$, as well as blood pressure (BP) $(p \leq 0.0021)$. The results were confirmed when comparing the HIV-infected group using ART $(N=85)$ and the HIV-uninfected group. When comparing the HIV-infected individuals with MetS to the HIV-uninfected individuals with MetS, no differences in BP were seen. With regard to renal function, the HIV-infected individuals with MetS $(n=32)$ had 43\% higher urinary albumin-creatinine ratio (uACR) compared to the HIV-uninfected individuals with MetS, after adjusting for age, sex and WC $(p=0.032)$. None of the other renal function markers differed after adjustments for WC or BMI.

Conclusion: The HIV-infected Africans with MetS had almost twofold higher uACR, despite the low prevalence of MetS, compared to their uninfected counterparts. The combination of HIV and MetS seemed to increase the risk for renal impairment.

\section{Introduction}

The global burden of the human immunodeficiency virus (HIV) continues to rise with approximately 38.8 million people being infected worldwide. Sub-Saharan Africa contributes $75.4 \%$ of new infections globally. ${ }^{1}$ In South Africa, the prevalence of HIV was estimated at 6.12 million for the year 2015..$^{2}$ The introduction of antiretroviral therapy (ART) to HIV-infected individuals has significantly improved mortality and morbidity, ${ }^{3}$ and HIV infection has now become a manageable chronic disease. ${ }^{4}$ However, the beneficial effects of ART are often overshadowed by comorbidities such as abnormal fat distribution, ${ }^{5}$ hypertension ${ }^{6}$ and dyslipidaemia. ${ }^{78}$

These comorbidities form part of metabolic syndrome (MetS), ${ }^{6,9}$ a multifaceted syndrome defined by a constellation of several cardiovascular risk factors. ${ }^{10,11}$ Metabolic syndrome is commonly reported among people living with HIV infection, and the prevalence is commonly affected by the type of ART regimen use. ${ }^{6,12} \mathrm{Met} S$ is also an independent risk factor for renal disease ${ }^{13}$, and it is not clear if it is the MetS per se or its individual components that are the cause of the observed renal impairment. ${ }^{13,14}$

Human immunodeficiency virus infection is independently associated with microalbuminuria among Black and White Americans. ${ }^{15}$ Furthermore, Okpa et al. ${ }^{16}$ reported the prevalence of microalbuminuria at $15 \%$ among newly diagnosed HIV-infected individuals in Nigeria. Microalbuminuria does not only reflect renal dysfunction but is also a marker of systemic endothelial damage, ${ }^{17}$ which is linked to an elevated risk of kidney damage, cardiovascular 
disease and mortality. ${ }^{18}$ Kidney disease contributes significantly to morbidity and mortality in HIV-infected individuals. ${ }^{19}$

Tenofovir disoproxil fumarate (TDF), part of the first-line ART regimen in South Africa since April 2010, ${ }^{20}$ is potentially nephrotoxic. $^{21}$ The prevalence of tenofovir-associated nephrotoxicity is estimated at $2.4 \%$, and the effect is considered to be mild and tolerable. ${ }^{22,23,24,25}$ Prolonged use of tenofovir affects kidney function more than any other nonnucleoside reverse transcriptase inhibitors.

Few studies report on the prevalence of MetS and the association thereof with renal function among the South African population living with HIV. As renal dysfunction is related to both the use of ART (tenofovir) and MetS, we hypothesise that the HIV-infected population using ART and suffering from MetS may be at particular risk for renal impairment. We reported the MetS prevalence in this cohort to be $21 \%$ when the individuals were newly diagnosed as being HIV-infected and ART-naïve in 2005. ${ }^{26}$ Therefore, the aim of this study is, first, to determine the prevalence of the MetS 10 years later and, second, to determine the association of MetS with renal function in a South African cohort infected with HIV.

\section{Methods}

\section{Study design and population}

The Prospective Urban and Rural Epidemiological (PURE) study is a multinational longitudinal study examining the changes in lifestyle and causes of chronic diseases, through periodic standardised data collection. ${ }^{27}$ The PURE study focuses on urban and rural areas in 17 different low- and middle-income countries, including South Africa. In the North-West Province of South Africa, the PURE study participants were randomly recruited door-to-door from two main sites: Potchefstroom (urban) and Ganyesa (rural), and they were followed for 10 years.

Black men and women older than 35 years were included in the PURE study. When we recruited, the HIV-infected individuals were unaware of their status and were newly identified as being HIV-infected. For this cross-sectional study, we matched data for $114 \mathrm{HIV}$-infected individuals with 114 HIV-uninfected participants according to age, sex and locality (urban and rural areas). Of the $114 \mathrm{HIV}$-infected participants, 27 had been infected with HIV for five years $(24 \%)$ and 87 were infected for 10 years $(76 \%)$. The participants $(n=228)$ had complete data sets for all MetS components.

\section{Questionnaires}

Questionnaires were used to collect data on socio-economic and demographic information, current health status, medical and family history, medication, as well as tobacco and alcohol use.

\section{Anthropometry}

Anthropometric measurements were performed according to standardised procedures, as prescribed by the guidelines of the International Society for the Advancement of Kinanthropometry (ISAK). ${ }^{28}$ We measured the height of the participants to the nearest $0.1 \mathrm{~cm}$ with a stadiometer (Leicester height measure, Seca, Birmingham, UK) and the weight of the participants to the nearest $0.1 \mathrm{~kg}$ on a portable electronic scale (Precision Health Scale, A \& D Company, Japan). Body mass index (BMI) was calculated. Waist circumference (WC) was recorded to the nearest $0.1 \mathrm{~cm}$ with a steel tape (Lufkin, Cooper Tools, Apex NC, USA).

\section{Blood pressure measurement}

The participants were allowed to rest for 10 minutes before blood pressure (BP) measurements were taken. Duplicate brachial BP measurements were taken in the sitting position at 5-min intervals, using the validated OMRON M6 device (Omron Healthcare, Kyoto, Japan). An appropriate cuff size was used, and it was placed on the right arm over the brachial artery, with the arm supported at heart level and in a relaxed position. Pulse pressure and mean arterial pressure were calculated. Duplicate central systolic blood pressure (cSBP) was measured with the Sphygmocor XCEL device (Atcor Medical Pty. Ltd., Sydney, Australia), with the participant in the supine position.

\section{Biological sample collection}

Prior to measurements, the participants were asked to fast overnight for a period of eight hours. A registered nurse collected the venous blood using a winged infusion set. The serum and plasma were prepared according to standardised procedures and were stored at $-80{ }^{\circ} \mathrm{C}$ until analysis. A spot urine sample was collected and stored at $-80^{\circ} \mathrm{C}$ until analysis.

\section{Biochemical analysis}

We analysed the serum samples with the Cobas Integra 400 plus (Roche Basel, Switzerland), and glucose, total cholesterol (TC), triglycerides (TG), low density lipoprotein cholesterol (LDL-c), high-density lipoprotein cholesterol (HDL-c), $\gamma$-glutamyl transferase (GGT) and creatinine levels were determined. Serum C-reactive protein (CRP) levels were determined by means of a particle-enhanced turbidimetric assay. Glycosylated haemoglobin (HbA1c) was determined using the D-10 Haemoglobin testing system (Bio-Rad, \#220-0101) by means of ion-exchange high-performance liquid chromatography.

We also analysed the urinary creatinine and albumin levels using the Cobas Integra 400 plus (Roche, Basel, Switzerland) by means of a kinetic colorimetric assay.

The inter- and intra-assay coefficients of variability for the biochemical analyses were as follows: glucose $(1.8 \% ; 2.1 \%)$, TC $(0.2 \% ; 1.9 \%)$, HDL-c $(1.1 \% ; 1.0 \%)$, LDL-c $(1.5 \% ; 1.9 \%)$, 
GGT (1.8\%; 1.8\%), CRP (1.3\%; 3.5\%), HbA1c (0.9\%; 1.3\%), creatinine $(1.4 \%, 2.5 \%)$ and albumin $(1.9 \% ; 2.2 \%)$.

\section{Human immunodeficiency virus testing and counselling}

Participants were counselled before and after HIV testing by a registered counsellor. The HIV status was determined from whole blood according to the protocols of the South African Department of Health, using the first response rapid HIV card test (Premier Medical Corporation Limited, Daman, India). In the case of a positive result, the test was confirmed with an Abon (Biopharm Corporation Limited Hanyzhou, China) rapid card test. For the CD4+ count analyses, fingerprick blood was collected and the CD4+ counts were determined at the research site using a point-of-care device, the PIMA ${ }^{\mathrm{TM}}$ CD4+ (Alere, Jena, Germany). Of the $114 \mathrm{HIV}-$ infected participants, $77.3 \%$ were using ART and were on the first-line ART regimen, namely the fixed dose combination compared to $22.7 \%$ that were ART-naïve. The fixed dose combination consisted of TDF, efavirenz (EFV) and emtricitabine (FTC) under different generic names but with the same active ingredients, namely, Tribuss, Atripla, Atroiza, Trivenz and Odimune.

\section{Metabolic syndrome definition}

We defined MetS using the criteria of the International Diabetes Federation (IDF): individuals with $\mathrm{WC}>94 \mathrm{~cm}$ for men and $>80 \mathrm{~cm}$ for women and any of the other two: BP $>130 / 85 \mathrm{mmHg}, \mathrm{TG}>1.7 \mathrm{mmol} / \mathrm{L}, \mathrm{HDL}-\mathrm{c}<1.03 \mathrm{mmol} / \mathrm{L}$ for men and $<1.29 \mathrm{mmol} / \mathrm{L}$ for women and glucose $>$ $5.6 \mathrm{mmol} / \mathrm{L}^{29}$

\section{Renal function}

Creatinine clearance $(\mathrm{mL} / \mathrm{min})$ was calculated using the Cockcroft-Gault formula as follows: ([140-age] * [weight in $\mathrm{kg}] *$ [1.23 if male OR 1.04 if female])/(serum creatinine in $\mu \mathrm{mol} / \mathrm{L}) .{ }^{21}$ For creatinine clearance $(\mathrm{CrCl})$, a cut-off value of $<50 \mathrm{~mL} / \mathrm{min}$ was chosen, as the South African Department of Health recommends the use of tenofovir to be discontinued below this cut-off point. ${ }^{30}$ We calculated the estimated glomerular filtration rate (eGFR) $\left(\mathrm{mL} / \mathrm{min} / 1.73 \mathrm{~m}^{2}\right)$ using the Chronic Kidney Disease Epidemiology Collaboration (CKD-EPI) equations. ${ }^{21}$ Black ethnicity was not included in the formula. ${ }^{31}$ We used the cut-off value of eGFR $<90 \mathrm{~mL} /$ $\mathrm{min} / 1.72 \mathrm{~m}^{2}{ }^{32}$ Urinary albumin creatinine ratio (uACR) was calculated and a cut-off value of $3 \mathrm{mg} / \mathrm{mmol}-30 \mathrm{mg} / \mathrm{mmol}$, which defines microalbuminuria, was used. ${ }^{21}$

\section{Statistical analysis}

We performed statistical analysis using Statistica version 13 (Stasoft Inc., Tulsa, OK). Descriptive statistics were done for all the normally distributed variables and were presented as means and standard deviations. Variables which were not normally distributed were log transformed and presented as geometric means and 5th and 95th percentiles.
An independent $t$-test was used to compare the means of the groups, and the Chi-square test was used for proportions of the categorical variables. Analyses of covariates were used to compare HIV-infected and HIV-uninfected groups while adjusting for WC. We also compared uACR between the HIV-infected with and without MetS, and the HIVuninfected with and without MetS, after adjusting for age, sex and WC. Bonferroni tests were used in post hoc comparisons between the groups. The adjusted least square means were used to plot a bar graph comparing the four groups mentioned. Finally, we performed multivariate adjusted regression analyses with renal markers $(\mathrm{CrCl}$, eGFR and uACR) as dependent variables in the total group, and in the HIV-uninfected and HIV-infected groups to determine the contributions of the MetS components towards renal function in the different groups. The independent variables that were entered into the model included age, sex, cSBP, WC, HDL-c, TG, HbA1C, CRP, MetS, HIV status, CD4+ cell count and ART. The significance level was set at $p \leq 0.05$.

\section{Ethical consideration}

Both the PURE study and this substudy were approved by the Health Research Ethics Committee (HREC) of the North-West University in South Africa (approval number: 00016-10-A1 and NWU-00035-16-S1). The study protocols conformed to the principles of the Declaration of Helsinki. The research information was conveyed in the participants' home language by trained African fieldworkers. The participants gave informed consent to take part in the study.

\section{Results}

Characteristics of the HIV-infected and matched HIVuninfected groups are presented in Table 1. As a result of matching age, sex and locality, the groups were similar. The HIV-infected group presented with lower prevalence of MetS than the HIV-uninfected group ( $28 \%$ vs. $44 \%, p=0.013)$. In those on ART $(N=85)$, the prevalence of MetS was $24.2 \%$.

The HIV-infected group had lower WC $(p<0.001)$ and BMI $(p<0.001)$ compared to the HIV-uninfected group. When comparing the cardiovascular measurements, the brachial systolic BP $(p=0.021)$, diastolic BP $(p=0.003), \operatorname{cSBP}(p=0.006)$ and mean arterial pressure $(p<0.001)$ were higher in the HIVuninfected group as compared to the HIV-infected group. With regard to the renal function measurements, the HIVinfected group had lower $\mathrm{CrCl}(p<0.001)$, but there was no difference in eGFR and $\mathrm{uACR}$.

After adjusting for WC, diastolic BP, mean arterial pressure and cSBP remained higher in the HIV-uninfected participants (Appendix 1, Table 1), but the brachial systolic BP $(p=0.057)$ and $\mathrm{CrCl}(p=0.304)$ no longer differed. When the same analysis was performed for BMI, similar results were observed. 
TABLE 1: Characteristics of the HIV-uninfected and HIV-infected individuals (2015).

\begin{tabular}{|c|c|c|c|}
\hline Variable & $\begin{array}{l}\text { HIV-uninfected } \\
\quad N=114\end{array}$ & $\begin{array}{l}\text { HIV-infected } \\
N=114\end{array}$ & $P$ \\
\hline Men, $N(\%)$ & $23(20.2)$ & $23(20.2)$ & - \\
\hline Age, years & $53.3 \pm 5.5$ & $53.4 \pm 5.6$ & 0.874 \\
\hline Urban $N(\%)$ & $46(40.4)$ & $46(40.4)$ & - \\
\hline \multicolumn{4}{|l|}{ Anthropometry } \\
\hline WC, $\mathrm{cm}$ & $91.6(70.5 ; 122.6)$ & $81.7(64.6 ; 109.1)$ & $<0.001$ \\
\hline $\mathrm{BMI}, \mathrm{kg} / \mathrm{m}^{2}$ & $27.4(18.0 ; 44.5)$ & $22.8(16.1 ; 34.5)$ & $<0.001$ \\
\hline \multicolumn{4}{|l|}{ Cardiovascular measurements } \\
\hline $\mathrm{SBP}, \mathrm{mmHg}$ & $133 \pm 21$ & $126 \pm 24$ & 0.021 \\
\hline $\mathrm{DBP}, \mathrm{mmHg}$ & $88 \pm 12$ & $83 \pm 14$ & 0.003 \\
\hline $\mathrm{PP}, \mathrm{mmHg}$ & $45 \pm 14$ & $43 \pm 15$ & 0.309 \\
\hline MAP, mmHg & $103 \pm 14$ & $97 \pm 16$ & 0.006 \\
\hline cSBP, mmHg & $129 \pm 18$ & $120 \pm 18$ & $<0.001$ \\
\hline \multicolumn{4}{|l|}{ Biochemical variables } \\
\hline $\mathrm{TC}, \mathrm{mmol} / \mathrm{L}$ & $4.53 \pm 1.60$ & $4.52 \pm 1.01$ & 0.904 \\
\hline LDL-c, mmol/L & $2.79 \pm 1.02$ & $2.67 \pm 0.89$ & 0.362 \\
\hline $\mathrm{TG}, \mathrm{mmol} / \mathrm{L}$ & $1.18(0.53 ; 2.85)$ & $1.10(0.50 ; 2.40)$ & 0.317 \\
\hline $\mathrm{HDL}-\mathrm{c}, \mathrm{mmol} / \mathrm{L}$ & $1.25(0.69 ; 2.27)$ & $1.32(0.74 ; 2.53)$ & 0.250 \\
\hline Glucose, $\mathrm{mmol} / \mathrm{L}$ & $5.34(3.85 ; 9.03)$ & $5.18(4.35 ; 6.48)$ & 0.529 \\
\hline $\mathrm{HbA1c}, \%$ & $5.92(5.00 ; 8.80)$ & $5.46(4.90 ; 6.30)$ & $<0.001$ \\
\hline $\mathrm{CRP}, \mathrm{mg} / \mathrm{L}$ & $1.11(0.05 ; 16.1)$ & $1.38(0.04 ; 43.7)$ & 0.072 \\
\hline $\mathrm{\gamma}$-glutamyltransferase, $\mathrm{U} / \mathrm{L}$ & $23.2(1.46 ; 256)$ & $23.4(0.70 ; 236)$ & 0.963 \\
\hline \multicolumn{4}{|l|}{ HIV-related parameters } \\
\hline CD4 cell count, cell/mm & - & $519 \pm 263$ & - \\
\hline$\leq 500$ cells $/ \mathrm{mm}^{3}, N(\%)$ & - & $54 / 106$ (50.9) & - \\
\hline$\leq 200$ cells $/ \mathrm{mm}^{3}, N(\%)$ & - & $9 / 106(8.5)$ & - \\
\hline \multicolumn{4}{|l|}{ Renal function } \\
\hline $\mathrm{SCr}, \mu \mathrm{mol} / \mathrm{L}$ & $55.9 \pm 11.4$ & $57.0 \pm 12.8$ & 0.499 \\
\hline $\mathrm{CrCl}, \mathrm{mL} / \mathrm{min}$ & $116(72.0 ; 208)$ & $97.9(56.9 ; 165)$ & $<0.001$ \\
\hline $\mathrm{CrCl}<50 \mathrm{~mL} / \mathrm{min}, N(\%)$ & $0 / 113$ & $1 / 113$ & 0.316 \\
\hline eGFR, $\mathrm{mL} / \mathrm{min} / 1.73 \mathrm{~m}^{2}$ & $103(83.2 ; 123)$ & $103(74.3 ; 120)$ & 0.985 \\
\hline $\begin{array}{l}\text { eGFR, }<90 \mathrm{~mL} / \mathrm{min} / 1.73 \mathrm{~m}^{2} \\
N(\%)\end{array}$ & $14(12.3)$ & $14(12.3)$ & 1.000 \\
\hline $\mathrm{uACR}, \mathrm{mg} / \mathrm{mmol}$ & $1.43(0.43 ; 14.6)$ & $1.89(0.52 ; 14.7)$ & 0.720 \\
\hline uACR, 3-30 mg/mmol, $N(\%)$ & 18/102 (17.7) & $27 / 100(27.0)$ & 0.110 \\
\hline \multicolumn{4}{|l|}{ Health behaviours } \\
\hline $\begin{array}{l}\text { Self-reported alcohol use, } \\
N(\%)\end{array}$ & $34 / 113(30.1)$ & $35 / 111(31.5)$ & 0.815 \\
\hline $\begin{array}{l}\text { Self-reported tobacco use, } \\
N(\%)\end{array}$ & $41 / 113(36.3)$ & $43 / 111(38.7)$ & 0.704 \\
\hline \multicolumn{4}{|l|}{ Medication use } \\
\hline Antihypertensive med, $N(\%)$ & $35(30.7)$ & 14/109 (12.8) & 0.001 \\
\hline Diuretics, $N(\%)$ & $38(33.3)$ & 20/109 (18.4) & 0.010 \\
\hline Statins, $N(\%)$ & $6(5.3)$ & $1 / 109(6.4)$ & 0.063 \\
\hline Anti-inflammatory med, $N(\%)$ & $8(7.0)$ & $7 / 109(6.4)$ & 0.859 \\
\hline Antidiabetic med, $N(\%)$ & $10(8.8)$ & $0 / 109(0.0)$ & 0.002 \\
\hline Anticoagulant med, $N(\%)$ & $9(7.9)$ & $3 / 109(2.8)$ & 0.089 \\
\hline $\begin{array}{l}\text { Antiretroviral therapy (ART), } \\
N(\%)\end{array}$ & - & $85 / 110(77.3)$ & - \\
\hline$\geq 5$ years on ART, $N(\%)$ & - & $38 / 59(64.4)$ & - \\
\hline Metabolic syndrome, $N(\%)$ & 50 (43.9) & $32(28.1)$ & 0.013 \\
\hline \multicolumn{4}{|c|}{$\begin{array}{l}\text { s.d., standard deviation; Cl, confidence interval; HIV, human immunodeficiency virus; } N \\
\text { number of participants; WC, waist circumference; BMI, body mass index; DBP, diastoli } \\
\text { blood pressure; SBP, systolic blood pressure; PP, pulse pressure, MAP, mean arterial pressure } \\
\text { cSBP, central systolic blood pressure; TC, Total cholesterol; LDL-cholesterol, low density } \\
\text { lipoprotein cholesterol; HDL-cholesterol, high-density lipoprotein- cholesterol; HbA1c\% } \\
\text { glycated haemoglobin; CRP, C-reactive protein; SCr, serum creatinine; } \mathrm{CrCl} \text {, creatinine } \\
\text { clearance; eGFR, estimated glomerular filtration rate; UACR, urinary albumin-creatinine } \\
\text { ratio; Med, medication; ART, antiretroviral therapy. }\end{array}$} \\
\hline \multicolumn{4}{|c|}{$\begin{array}{l}\text { Data are arithmetic mean } \pm \text { s.d. or geometric mean ( } 5 \text { th and } 95 \text { th percentile intervals) fo } \\
\text { logarithmically transformed variables. }\end{array}$} \\
\hline
\end{tabular}

To determine the potential influence of ART, we repeated the comparative analyses between the HIV-uninfected and the HIV-infected groups using ART $(N=85)$ (Appendix 1 , Table 2). The results remained the same.
TABLE 2: Characteristics of the HIV-uninfected and HIV-infected individuals with the metabolic syndrome.

\begin{tabular}{|c|c|c|c|}
\hline Variable & $\begin{array}{l}\text { HIV-uninfected } \\
\text { with MetS } \\
N=\mathbf{5 0}\end{array}$ & $\begin{array}{c}\text { HIV-infected } \\
\text { with MetS } \\
N=\mathbf{3 2}\end{array}$ & $P$ \\
\hline Men, $N(\%)$ & $5(10.0)$ & $4(12.5)$ & 0.723 \\
\hline Age, years & $53.8 \pm 6.5$ & $53.5 \pm 6.1$ & 0.844 \\
\hline Urban $N(\%)$ & $19(38.0)$ & $16(50.0)$ & 0.283 \\
\hline \multicolumn{4}{|l|}{ Anthropometry } \\
\hline $\mathrm{WC}, \mathrm{cm}$ & $102(85.5 ; 129)$ & $94.6(80.0 ; 120.3)$ & 0.023 \\
\hline $\mathrm{BMI}, \mathrm{kg} / \mathrm{m}^{2}$ & $32.6(24.4 ; 50.0)$ & $27.8(19.0 ; 44.0)$ & 0.010 \\
\hline \multicolumn{4}{|l|}{ Cardiovascular measurements } \\
\hline $\mathrm{SBP}, \mathrm{mmHg}$ & $139 \pm 12$ & $137 \pm 29$ & 0.782 \\
\hline $\mathrm{DBP}, \mathrm{mmHg}$ & $91 \pm 10$ & $90 \pm 14$ & 0.789 \\
\hline $\mathrm{PP}, \mathrm{mmHg}$ & $48 \pm 11$ & $47 \pm 19$ & 0.839 \\
\hline MAP, $\mathrm{mmHg}$ & $107 \pm 09$ & $106 \pm 18$ & 0.772 \\
\hline cSBP, $\mathrm{mmHg}$ & $133 \pm 15$ & $129 \pm 20$ & 0.457 \\
\hline \multicolumn{4}{|l|}{ Biochemical variables } \\
\hline $\mathrm{TC}, \mathrm{mmol} / \mathrm{L}$ & $4.54 \pm 1.07$ & $4.66 \pm 1.16$ & 0.699 \\
\hline LDL-c, mmol/L & $2.88 \pm 1.11$ & $2.69 \pm 1.00$ & 0.523 \\
\hline $\mathrm{TG}, \mathrm{mmol} / \mathrm{L}$ & $1.47(0.28 ; 2.72)$ & $1.66(0.67 ; 6.70)$ & 0.432 \\
\hline $\mathrm{HDL}-\mathrm{c}, \mathrm{mmol} / \mathrm{L}$ & $1.02(0.77 ; 1.61)$ & $1.34(0.55 ; 2.34)$ & 0.316 \\
\hline Glucose, $\mathrm{mmol} / \mathrm{L}$ & $5.71(3.84 ; 12.9)$ & $5.56(4.35 ; 7.96)$ & 0.684 \\
\hline $\mathrm{HbA} 1 \mathrm{c}, \%$ & $6.28(5.20 ; 11.7)$ & $5.71(5.10 ; 6.60)$ & 0.040 \\
\hline $\mathrm{CRP}, \mathrm{mg} / \mathrm{L}$ & $1.04(0.05 ; 15.6)$ & $1.50(0.04 ; 29.6)$ & 0.555 \\
\hline $\mathrm{V}$-glutamyltransferase, $\mathrm{U} / \mathrm{L}$ & $22.7(2.01 ; 224)$ & $25.6(0.70 ; 325)$ & 0.797 \\
\hline \multicolumn{4}{|l|}{ HIV-related parameters } \\
\hline CD4 cell count, cell $/ \mathrm{mm}^{3}$ & - & $497 \pm 239$ & - \\
\hline$\leq 500$ cells $/ \mathrm{mm}^{3}, N(\%)$ & - & $15 / 30(50)$ & - \\
\hline$\leq 200$ cells $/ \mathrm{mm}^{3}, N(\%)$ & - & $2 / 30(6.7)$ & - \\
\hline \multicolumn{4}{|l|}{ Renal function } \\
\hline $\mathrm{SCr}, \mu \mathrm{mol} / \mathrm{L}$ & $55.9 \pm 12.2$ & $57.0 \pm 12.8$ & 0.694 \\
\hline $\mathrm{CrCl}, \mathrm{mL} / \mathrm{min}$ & $133(86.5 ; 218)$ & $113(71.3 ; 192)$ & 0.050 \\
\hline $\mathrm{CrCl}<50 \mathrm{~mL} / \mathrm{min}, N(\%)$ & - & - & - \\
\hline eGFR, $\mathrm{mL} / \mathrm{min} / 1.73 \mathrm{~m}^{2}$ & $100(87.2 ; 112)$ & $104(82.5 ; 129)$ & 0.211 \\
\hline eGFR, $<90 \mathrm{~mL} / \mathrm{min} / 1.73 \mathrm{~m}^{2}, N(\%)$ & $7(14.0)$ & $3(9.38)$ & 0.532 \\
\hline $\mathrm{uACR}, \mathrm{mg} / \mathrm{mmol}$ & $1.43(0.49 ; 20.5)$ & $2.80(0.47 ; 25.8)$ & 0.065 \\
\hline uACR, 3-30 mg/mmol, $N(\%)$ & $8 / 46(17.4)$ & $13 / 28(46.4)$ & 0.007 \\
\hline \multicolumn{4}{|l|}{ Health behaviours } \\
\hline Self-reported alcohol use, $N(\%)$ & 9/49 (18.4) & $10(31.3)$ & 0.181 \\
\hline Self-reported tobacco use, $N(\%)$ & $14 / 49(28.6)$ & $12(37.5)$ & 0.400 \\
\hline \multicolumn{4}{|l|}{ Medication use } \\
\hline $\begin{array}{l}\text { Antihypertensive medication, } \\
N(\%)\end{array}$ & $22(44.0)$ & $8(25.0)$ & 0.081 \\
\hline Diuretics, $N(\%)$ & $24(48.0)$ & $9(25.1)$ & 0.073 \\
\hline Statins, $N(\%)$ & $3(6.0)$ & $0(0.0)$ & 0.158 \\
\hline $\begin{array}{l}\text { Anti-inflammatory medication, } \\
N(\%)\end{array}$ & $4(8.0)$ & $2(6.3)$ & 0.766 \\
\hline Antidiabetic medication, $N(\%)$ & $9(18)$ & $0(0.0)$ & 0.011 \\
\hline Anticoagulant medication, $N(\%)$ & $6(12.0)$ & $2(6.3)$ & 0.392 \\
\hline Antiretroviral therapy (ART), $N(\%)$ & - & $24(75.0)$ & - \\
\hline$\geq 5$ years on ART, $N(\%)$ & - & $14 / 22(14.0)$ & - \\
\hline
\end{tabular}

s.d., standard deviation; $\mathrm{Cl}$, confidence interval; HIV, human immunodeficiency virus; $N$ number of participants; WC, waist circumference; BMI, body mass index; DBP, diastolic blood pressure; SBP, systolic blood pressure; PP, pulse pressure, MAP, mean arterial pressure CSBP, central systolic blood pressure; TC, Total cholesterol; LDL-cholesterol, low density lipoprotein cholesterol; HDL-cholesterol, high-density lipoprotein- cholesterol; $\mathrm{HbA} 1 \mathrm{c} \%$, glycated haemoglobin; CRP, C-reactive protein; $\mathrm{SCr}$, serum creatinine; $\mathrm{CrCl}$, creatinine clearance; eGFR, estimated glomerular filtration rate; UACR, urinary albumin-creatinine ratio; Med, medication; ART, antiretroviral therapy.

Data are arithmetic mean \pm s.d. or geometric mean (5th and 95th percentile intervals) for logarithmically transformed variables.

We further compared HIV-infected group with MetS and HIVuninfected group with MetS (Table 2). The BPs did not differ between the groups. However, in the HIV-infected group, the WC $(p=0.023), \mathrm{BMI}(p=0.010)$ and $\mathrm{CrCl}(p=0.050)$ were lower. 


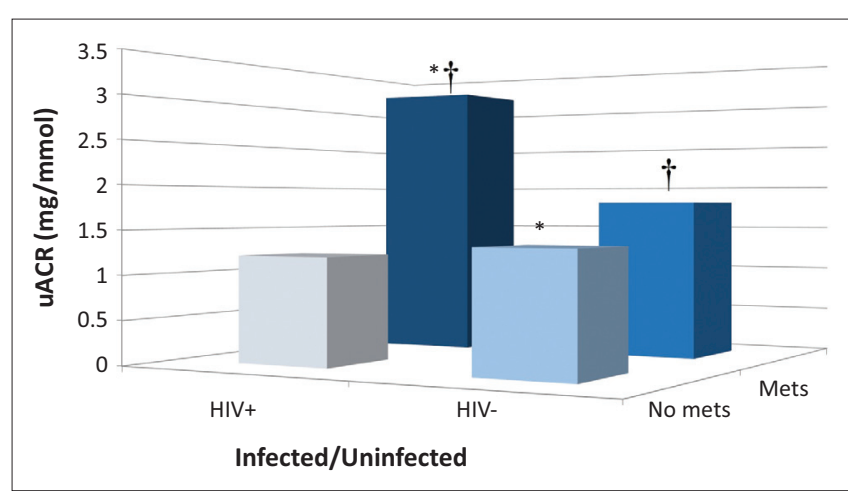

HIV, human immunodeficiency virus; HIV+, infected with human immunodeficiency virus; HIV-, human immunodeficiency virus uninfected; MetS, metabolic syndrome; UACR, urinary albumin-creatinine ratio (UACR). Bars with the same symbol differ significantly.

$\dagger p=0.032 ; * p=0.047$

FIGURE 1: Urinary albumin excretion for HIV-uninfected and HIV-infected individuals with and without metabolic syndrome after adjusting for age, sex and waist circumference.

However, after adjusting for WC (119 [109; 130] vs. 128 [119; 137]; $p=0.213)$ or BMI $(120$ [111; 131] vs. 127 [119; 136]; $p=0.316)$, the difference in $\mathrm{CrCl}$ disappeared. Furthermore, of this group, a greater proportion had microalbuminuria $(46 \%$ vs. $17 \%, p=0.007$ ) compared to the uninfected group, supported by a tendency of higher uACR in the HIV-infected group with MetS (2.80 mg/mmol vs. $1.43 \mathrm{mg} / \mathrm{mmol}, p=0.065)$.

We also compared uACR between the HIV-infected and HIVuninfected groups, with and without MetS (Figure 1), while adjusting for age, sex and WC. The mean uACR of the HIVinfected group with MetS $(3.16 \mathrm{mg} / \mathrm{mmol}$ ) was almost double that of the HIV-uninfected group with MetS (1.81 mg/ mmol) $(p=0.032)$ despite similar ages and BPs. When comparing the HIV-infected group without MetS to those with MetS, the uACR tended to be lower $(1.21 \mathrm{mg} / \mathrm{mmol}$; $p=0.11)$. The uACR was also lower in the HIV-uninfected group without MetS $(1.34 \mathrm{mg} / \mathrm{mmol})$, compared to the HIVinfected group with MetS ( $p=0.047)$.

We performed multiple regression analysis for renal markers ( $\mathrm{CrCl}$, eGFR and $\mathrm{uACR})$ in the total group, HIV-uninfected and HIV-infected groups (Table 3). In the total group, the presence of MetS was positively associated with eGFR $(p=0.008)$.

In both the HIV-infected and HIV-uninfected groups, age, WC and TG were associated with $\mathrm{CrCl}$, and age was negatively associated with eGFR. In the HIV-infected group, CD4+ cell count was positively associated with $\mathrm{CrCl}$ $(p=0.009)$. The use of ART did not associate with any markers of renal function. When viewing the results for $\mathrm{uACR}$, female sex was associated with increased $\mathrm{UACR}$ in the total group $(p=0.001)$ and the HIV-uninfected group $(p=0.001)$, and was borderline in the HIV-infected group $(p=0.086)$. In the total group $(p<0.001)$, the HIV-uninfected group $(p<0.001)$ and the HIV-infected group $(p=0.008)$, uACR was also positively associated with cSBP. We also observed that UACR was negatively associated with WC in the total group $(p<0.001)$, the HIV-uninfected group $(p<0.001)$ and the HIV-infected group $(p=0.049)$. In the HIV-infected group, the presence of MetS was positively associated with eGFR $(p=0.039)$ and had a borderline association with uACR $(p=0.059)$.

\section{Sensitivity analyses}

We repeated the regression analyses and excluded participants not using ART $(N=29)$. The results as presented in Appendix 1, Table 3, remained largely unchanged. For eGFR, the contribution of MetS became weaker $(\beta=0.21$; $p=0.15)$, but for uACR the contribution of MetS became stronger $(\beta=0.36 ; p=0.017)$.

\section{Discussion}

We aimed to determine the prevalence of MetS and to evaluate the renal function in a South African cohort infected with HIV for at least five years. Our main finding was that Africans with HIV infection and MetS had a $43 \%$ higher urinary albumin excretion compared to the HIV-uninfected with MetS. However, it is also noteworthy that only $28 \%$ of the HIV-infected group had MetS, compared to $44 \%$ of their matched, uninfected counterparts.

The latter is in agreement with a cross-sectional study by Jacobson et al..$^{33}$ who reported a lower prevalence of MetS in HIV-infected group as opposed to HIV-uninfected group. We reported a prevalence of $21 \%$ in this study population 10 years earlier when they were ART-naïve. ${ }^{26}$ Our current finding of a prevalence of MetS of $28 \%$ among the HIVinfected Black people is supported by Julius et al. ${ }^{8}$ who reported a prevalence of $20 \%$ among Black South Africans using ART. Hirigo and Tesfaye $\mathrm{e}^{34}$ reported a similar prevalence of $24 \%$ using the IDF critique among Ethiopian HIV-infected individuals on ART. In contrast, other studies have reported a higher prevalence of MetS in HIV-infected individuals, compared to the uninfected. $6,12,35$ In this study, the HIVinfected group had lower obesity and BP measurements, with no differences in lipid and glucose levels, whereas in previous studies the HIV-infected individuals with MetS had a higher prevalence, which was driven by a higher prevalence of impaired metabolic components. The IDF criteria require central obesity as a prerequisite and any other two metabolic components to meet the criteria of MetS. ${ }^{36}$ The lower obesity and BPs in our HIV cohort may explain the lower prevalence of MetS in the HIV-infected participants.

In our study, the majority of HIV-infected participants (77\%) were taking ART, which is associated with improved immune status $^{30}$ and either improvement or alteration of MetS components. ${ }^{6,37}$ However, different ART regimens may exert different effects on the metabolic components, 5,6 which may further explain the lower WC and BP among those on ART in this study. An observational study including HIV-infected participants on ART (with TDF and EFV as part of the regimen) also reported no association between the use of ART and BP among Indians, ${ }^{38}$ while Kaplan et al. ${ }^{39}$ reported a lower prevalence of overweight and hypertension among the HIV-infected individuals, compared to HIV-uninfected individuals. However, when we compared the HIV-infected 
TABLE 3: Multiple regression analysis with markers of renal function as dependent variables.

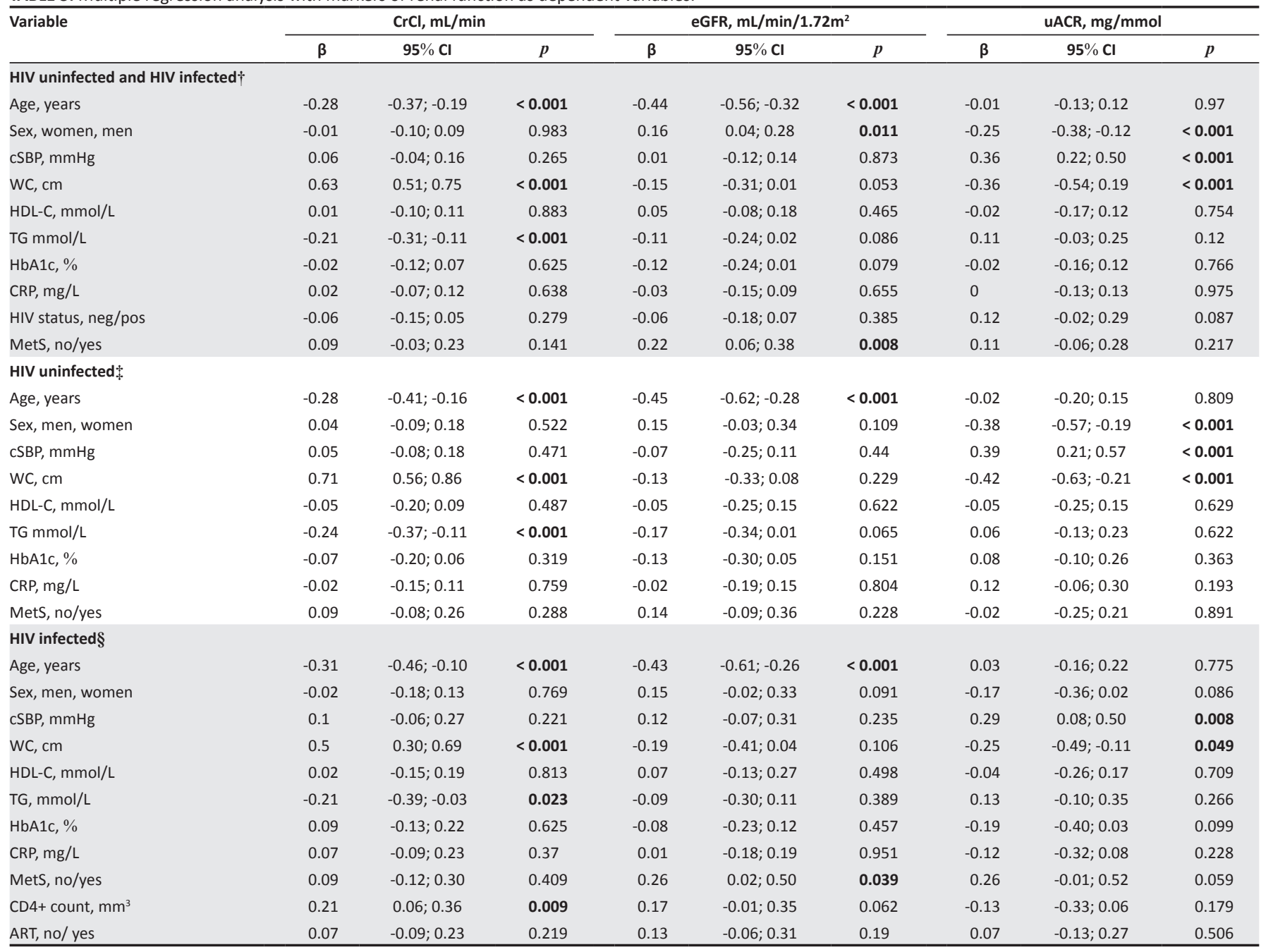

t, HIV-uninfected and HIV-infected $(N=228): \mathrm{CrCl}, \mathrm{mL} / \mathrm{min}-R^{2}=0.533 ; \mathrm{eGFR}, \mathrm{mL} / \mathrm{min} / 1.72 \mathrm{~m} 2, R^{2}=0.227 ; \mathrm{uACR}, \mathrm{mg} / \mathrm{mmol}-R^{2}=0.202$.

\$, HIV-uninfected $(N=114)$ : $\mathrm{CrCl}, \mathrm{mL} / \mathrm{min}-R^{2}=0.583 ; \mathrm{eGFR}, \mathrm{mL} / \mathrm{min} / 1.72 \mathrm{~m}^{2}-R^{2}=0.232 ; \mathrm{uACR}, \mathrm{mg} / \mathrm{mmol}-R^{2}=0.270$.

$\S$, HIV-infected $(N=114): \mathrm{CrCl}, \mathrm{mL} / \mathrm{min}-R^{2}=0.425 ; \mathrm{eGFR}, \mathrm{mL} / \mathrm{min} / 1.72 \mathrm{~m}^{2}-R^{2}=0.231 ; \mathrm{UACR}, \mathrm{mg} / \mathrm{mmol}-R^{2}=0.152$.

Significance of data set in bold.

Total group (HIV-uninfected and HIV-infected, $N=228$ ).

$\beta$, partial regression coefficient; $R^{2}$, adjusted $R^{2} ; 95 \% \mathrm{Cl}, 95 \%$ confidence interval of $\beta$; HIV, human immunodeficiency syndrome; N, number of participants; eGFR, estimated glomerular filtration rate; $\mathrm{UACR}$, urinary albumin creatinine ratio; $\mathrm{CrCl}$, creatinine clearance; $\mathrm{CSBP}$, central systolic blood pressure; WC, waist circumference; HDL-C, high-density lipoprotein cholesterol; TG, triglycerides; $\mathrm{HbA1c} \%$, glycated haemoglobin; CRP, C-reactive protein; MetS, metabolic syndrome; pos, HIV positive; neg, HIV negative; ART, antiretroviral therapy.

eGFR, UACR, CrCl, CSBP, WC, HDL-C, TG, CRP were logarithmically transformed. Independent variables included in the model include: age, sex, CSBP, WC, HDL-C, TG, HbA1C, CRP, CD ${ }^{4}$ cell count and ART. All independent variables were added at the same time. Bold values indicate $p \leq 0.05$.

participants with MetS and HIV-uninfected participants with MetS, no differences were seen in the BP measurements. This indicated the important role of BP in the development of MetS, which may be independent of HIV status.

Without considering the prevalence of MetS, we found that $27 \%$ of the HIV-infected individuals had microalbuminuria compared to only $18 \%$ of the HIV-uninfected individuals. Szczech et al. ${ }^{15}$ reported a higher prevalence of urinary albumin excretion in an HIV-infected group as compared to uninfected counterparts $(11 \%$ vs. $2 \%)$. Okpa et al. ${ }^{16}$ also reported a prevalence of $15 \%$ of microalbuminuria among newly diagnosed HIV-infected Nigerians. However, the latter two studies did not assess MetS.

We aimed to determine whether renal function is affected in those with both HIV and MetS. Microalbuminuria was considerably higher in the HIV-infected individuals with
MetS (46\%) compared to their uninfected counterparts (17\%), despite similar ages and gender distribution. This supports the role of MetS in early renal dysfunction in HIV-infected patients. Our finding of $46 \%$ microalbuminuria is higher than a recent report by Pirro et al., ${ }^{40}$ indicating a prevalence of $17 \%$ of microalbuminuria in the HIV-infected with MetS in Italy. However, a control group was not included in the latter study.

Urinary albumin excretion is a well-known marker of renal dysfunction and may precede systematic endothelial dysfunction, ${ }^{18}$ with glomerular permeability to albumin increasing as endothelial dysfunction develops. ${ }^{41}$ Metabolic syndrome is frequently reported in HIV-infected individuals on ART and is associated with both microalbuminuria and endothelial dysfunction. ${ }^{40}$ Furthermore, HIV may directly infect the glomerular epithelial cells, resulting in excretion of albumin. ${ }^{42}$ As tenofovir has nephrotoxic potential, ${ }^{43}$ 
it mayfurther augment the effect of the HIV infection on the kidneys. Tubular toxicity as a result of tenofovir exposure is frequently reported; however, these reports are controversial. ${ }^{22}$ Glomerular damage may occur as a result of factors such as diabetes, hypertension, MetS and HIV infection which then alter permeability to macromolecules such as albumin and other proteins. ${ }^{41,42}$ In this study, we did not screen the HIVinfected participants for proteinuria, which might have shed some insights into whether the elevated albumin excretion is because of glomerular damage or tubular toxicity. However, in the multivariate analyses, we did not observe an association between the use of ART and the renal function markers in the HIV-infected individuals. Thus, the combination of the MetS, HIV and tenofovir may exacerbate the glomerular permeability, explaining the high albumin excretion in our participants with both MetS and HIV infection.

In the multivariate analyses, renal function was associated with cardiovascular risk factors rather than HIV-associated factors, and ART was not associated with any of the renal function markers. Some studies have reported improvements in renal function with the use of ART and suppressed viral load. ${ }^{44,45}$ In our study, a CD4+ cell count was beneficially associated with $\mathrm{CrCl}$ and eGFR, showing that improved immune systems may protect against renal dysfunction. ${ }^{45} \mathrm{In}$ addition, during the pre-ART era, the prevalence of microalbuminuria (defined by $\mathrm{uACR} \geq 3 \mathrm{mg} / \mathrm{mmol}-30 \mathrm{mg} /$ $\mathrm{mmol}$ ) in HIV-infected individuals was estimated at between $19 \%$ and $31 \%, 19,46$ whereas in the post-ART era, it was estimated at between $8.7 \%$ and $11 \%{ }^{47}$

Urinary albumin excretion is an important marker of renal dysfunction and cardiovascular disease risk, even at subclinical levels. Utilisation of uACR may prove beneficial as it is suggested that the substantial renal impairment seen in individuals taking tenofovir is because of pre-existing renal dysfunction, which might be intensified with tenofovir. ${ }^{48}$ It may help to identify HIV-infected individuals with MetS who are potentially at higher risk of renal dysfunction.

\section{Limitations of the study}

This study should be interpreted within the context of its strengths and potential limitations. A limitation of our study is the small sample size of those with MetS. However, the HIV-infected individuals were infected for at least five years and were matched according to age, sex and locality to a control group in order to limit confounders. There were incomplete data on the duration of the ART, but we were ableto determine duration of at least five years, and the participants were on standard first-line triple therapy fixed dose combinations. Tuberculosis testing was not performed for this study; however, information on chronic medication was available. As this was a cross-sectional study, the associations do not indicate cause and effect. This is a wellcontrolled study, and to our knowledge, this is the first study to investigate the combination of MetS and renal function in an African cohort infected with HIV.

\section{Conclusion}

In conclusion, HIV-infected Africans with MetS had an almost twofold higher urinary albumin excretion compared to the HIV-uninfected controls with MetS. The combination of HIV and MetS indicated an elevated risk for the development of renal disease and cardiovascular disease, and could increase the risk of cardiovascular morbidity and mortality in HIV-infected individuals.

\section{Acknowledgements}

The authors are grateful to all the participants who voluntarily took part in the study, the PURE-SA research team and the fieldworkers, North-West University, South Africa, as well as Dr S. Yusuf (PURE-International) and the PURE project team at Hamilton Health Sciences at the McMaster University, ON, Canada.

\section{Competing interests}

The authors declare that they have no financial or personal relationships that may have inappropriately influenced them in writing this article.

\section{Authors' contributions}

E.P. was responsible for the literature search, data analysis, interpretation of data and writing of the manuscript. C.M.T.F. and A.E.S. were responsible for the conception and design, acquisition and interpretation of data and for revising the article critically for intellectual content. All authors approved the final version.

\section{References}

1. Wang $\mathrm{H}$, Wolock TM, Carter A, et al. Estimates of global, regional, and national incidence, prevalence, and mortality of HIV, 1980-2015: The Global Burden of Disease Study 2015. Lancet HIV. 2016;3(8):e361-e387. https://doi.org/10.1016/ S2352-3018(16)30087-X

2. Statistics South Africa. Mid-year population estimates [homepage on the Internet]. 2015 [cited 2016 Apr 13]. Available from: https://www.statssa.gov.za/ publications/P0302/P03022015.pdf

3. World Health Organization. Guideline on when to start antiretroviral therapy and on pre-exposure prophylaxis for HIV [homepage on the Internet]. 2015 [cited 2016 May 08]. Available from: www.who.int/hiv/pub/guidelines/earlyreleasearv/en

4. Oni T, Youngblood E, Boulle A, McGrath N, Wilkinson RJ, Levitt NS. Patterns of HIV, $\mathrm{TB}$, and non-communicable disease multi-morbidity in peri-urban South Africa - A cross sectional study. BMC Infect Dis. 2015;15(1):1-8. https://doi.org/10.1186/ s12879-015-0750-1

5. Berhane T, Yami A, Alemseged F, et al. Prevalence of lipodystrophy and metabolic syndrome among HIV positive individuals on highly active anti-retroviral treatment in Jimma, South West Ethiopia. Pan Afr Med ] [serial online]. 2013[cited 2018 Aug 16];13(1):1-4. Available from: https://www.ncbi.nlm.nih.gov/pmc/ 2018 Aug 16];13(1):1-4. Available from:
articles/PMC3542806/pdf/PAMJ-13-43.pdf

6. Mbunkah HA, Meriki HD, Kukwah AT, Nfor O, Nkuo-Akenji T. Prevalence of metabolic syndrome in human immunodeficiency virus-infected patients from
the South-West region of Cameroon, using the adult treatment panel III the South-West region of Cameroon, using the adult treatment panel III
criteria. Diabetol Metabol Syndr. 2014;6(1):92. https://doi.org/10.1186/17585996-6-92

7. Souza SJ, Luzia LA, Santos SS, Rondó PHC. Lipid profile of HIV-infected patients in relation to antiretroviral therapy: A review. Rev Assoc Med Bras. 2013;59(2): 186-198. https://doi.org/10.1016/j.ramb.2012.11.003

8. Julius H, Basu D, Ricci E, et al. The burden of metabolic diseases amongst HIV positive patients on HAART attending the Johannesburg Hospital. Curr HIV Res. 2011;9(4):247-252. https://doi.org/10.2174/157016211796320360

9. Grundy SM. Metabolic syndrome: Connecting and reconciling cardiovascular and diabetes worlds. J Am Coll Cardiol. 2006;47(6):1093-1100. https://doi.org/ 10.1016/j.jacc.2005.11.046 
10. Eckel RH, Kahn R, Robertson RM, Rizza RA. Preventing cardiovascular disease and diabetes A call to action from the American Diabetes Association and the American Heart Association. Circulation. 2006:113(25):2943-2946. https://doi. org/10.2337/dc06-9911

11. Grundy SM. Metabolic syndrome pandemic. Arterioscler Thromb Vasc Biol. 2008;28(4):629-636. https://doi.org/10.1161/ATVBAHA.107.151092

12. Tesfaye DY, Kinde S, Medhin G, et al. Burden of metabolic syndrome among HIVinfected patients in Southern Ethiopia. Diabetes Metab Syndr Clin Res Rev. 2014;8(2):102-107. https://doi.org/10.1016/j.dsx.2014.04.008

13. Gluba A, Mikhailidis DP, Lip GY, Hannam S, Rysz J, Banach M. Metabolic syndrome and renal disease. Int J Cardiol. 2013;164(2):141-150. https://doi.org/10.1016/j. ijcard.2012.01.013

14. Rashidi A, Ghanbarian A, Azizi F. Are patients who have metabolic syndrome without diabetes at risk for developing chronic kidney disease? Evidence based on data from a large cohort screening population. Clin J Am Soc Nephrol [serial online]. 2007 [cited 2018 Feb 02];2(5):976-983. https://doi.org/10.2215/ CJN.01020207. Available from: http://cjasn.asnjournals.org/content/2/5/976. long

15. Szczech LA, Grunfeld C, Scherzer R, et al. Microalbuminuria in HIV infection. AIDS (London, England). 2007;21(8):1003. https://doi.org/10.1097/QAD.0b013e328 Od3587f

16. Okpa H, Oviasu E, Ojogwu L. Microalbuminuria and its relationship with clinical and biochemical parameters in newly diagnosed HIV patients in a Tertiary Hospital South-South Nigeria. World J Med Sci. 2015;12(2):83-90. https://doi.org/10.5829/ idosi.wjms.2015.12.2.92106

17. Efstratiadis G, Tziomalos K, Mikhailidis DP, Athyros VG, Hatzitolios A. Atherogenesis in renal patients: A model of vascular disease? Curr Vasc Pharmacol. 2008:6(2):93in renal patients: A model of vascular disease? Curr Vasc
107. https://doi.org/10.2174/157016108783955374

18. Baekken M, Os I, Sandvik L, Oektedalen O. Microalbuminuria associated with indicators of inflammatory activity in an HIV-positive population. Nephrol Dial Transplant. 2008;23(10):3130-3137. https://doi.org/10.1093/ndt/gfn236

19. Sarafidis PA, Bakris GL. Microalbuminuria and chronic kidney disease as risk factors for cardiovascular disease. Nephrol Dial Transplant 2006;21(9):23662374. https://doi.org/10.1093/ndt/gfl309

20. South African Department of Health. South African antiretroviral guidelines [homepage on the Internet]. 2010 [cited 2016 Apr 08]. Available from: http:// apps.who.int/medicinedocs/documents/s19153en/s19153en.pdf

21. Lucas GM, Ross MJ, Stock PG, et al. Clinical practice guideline for the management of chronic kidney disease in patients infected with HIV: 2014 update by the HIV Medicine Association of the Infectious Diseases Society of America. Clin Infec Dis. 2014;59:e96-138. https://doi.org/10.1093/cid/ciu617

22. Reid A, Stöhr W, Walker AS, et al. Severe renal dysfunction and risk factors associated with renal impairment in HIV-infected adults in Africa initiating antiretroviral therapy. Clin Infec Dis. 2008;46(8):1271-1281. https://doi.org/ $10.1086 / 533468$

23. Kinai $E$, Hanabusa $\mathrm{H}$. Progressive renal tubular dysfunction associated with longterm use of tenofovir DF. AIDS Res Hum Retroviruses. 2009;25(4):387-394. https://doi.org/10.1089/aid.2008.0202

24. Fux CA, Simcock $M$, Wolbers $M$, et al. Tenofovir use is associated with a reduction in calculated glomerular filtration rates in the Swiss HIV Cohort Study. Antiviral Ther [serial online]. 2007;12(8):1165. Available from: https://www.ncbi.nlm.nih.

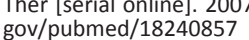

25. Winston A, Amin J, Mallon $P$, et al. Minor changes in calculated creatinine clearance and anion-gap are associated with tenofovir disoproxil fumaratecontaining highly active antiretroviral therapy. HIV Med. 2006;7(2):105-111. https://doi.org/10.1111/j.1468-1293.2006.00349.x

26. Fourie CMT, Van Rooyen JM, Kruger A, Schutte AE. Lipid abnormalities in a nevertreated HIV-1 subtype C-infected African population. Lipids. 2010;45(1):73-80. https://doi.org/0.1007/s11745-009-3369-4

27. Teo K, Chow CK, Vaz M, Rangarajan S, Yusuf S. The Prospective Urban Rura Epidemiology (PURE) study: Examining the impact of societal influences on chronic noncommunicable diseases in low-, middle-, and high-income countries. Am Heart J. 2009;158(1):1-7. https://doi.org/10.1016/j.ahj.2009.04.019

28. Marfell-Jones $M$, Olds $T$, Stewart A, Carter L. International standards for anthropometric assessment. Potchefstroom, South Africa: International Society for the Advancement of Kinanthropometry (ISAK) [homepage on the Internet]. ISBN Report. 2006 [cited 2018 Feb 02]. Available from: https://www.researchgate. net/publication/236891109_International_Standards_for_Anthropometric Assessment
29. International Diabetes Federation. The IDF consensus worldwide definition of the metabolic syndrome [homepage on the Internet]. 2006 [cited 2016 May 13]. Available from: http://www.idf.org/webdata/docs/MetS_def_update2006.pdf

30. South African Department of Health. National consolidated guidelines for the prevention of mother-to-child transmission HIV (PMCTCT) and the management of HIV in children and adolescents and adults [homepage on the Internet]. 2015 [cited 2016 Apr 13]. Available from: www.sahivsoc.org/upload...ART\%20 Guidelines\%2015052015.pdf

31. Seape T, Gounden V, van Deventer HE, Candy GP, George JA. Cystatin C-and creatinine-based equations in the assessment of renal function in HIV-positive patients prior to commencing highly active antiretroviral therapy. Ann Clin Biochem. 2016;53(1):58-66. https://doi.org/0.1177/0004563215579695

32. Overton E, Nurutdinova D, Freeman J, Seyfried W, Mondy K. Factors associated with renal dysfunction within an urban HIV-infected cohort in the era of highly active antiretroviral therapy. HIV Med. 2009;10(6):343-350. https://doi. org/10.1111/j.1468-1293.2009.00693.x

33. Jacobson DL, Tang AM, Spiegelman D, et al. Incidence of metabolic syndrome in a cohort of HIV-infected adults and prevalence relative to the US population (National Health and Nutrition Examination Survey). J Acquir Immune Defic Syndr. 2006;43(4):458-466. https://doi.org/10.1097/01.qai.0000243093.34652.41

34. Hirigo AT, Tesfaye DY. Influences of gender in metabolic syndrome and its components among people living with HIV virus using antiretroviral treatment in Hawassa, southern Ethiopia. BMC Res Notes. 2016;9(1):1. https://doi.org/ 10.1186/s13104-016-1953-2

35. Bonfanti P, Giannattasio C, Ricci E, et al. HIV and metabolic syndrome: A comparison with the general population. J Acquir Immune Defic Syndr 2007;45(4):426-431. https://doi.org/10.1097/QAl.0b013e318074ef83

36. Alberti KGMM, Zimmet $P$, Shaw J. Metabolic syndrome - A new world-wide definition. A consensus statement from the international diabetes federation Diabetic Med. 2006;23(5):469-480. https://doi.org/10.1016/S0140-6736(05)674028

37. Dillon DG, Gurdasani D, Riha J, et al. Association of HIV and ART with cardiometabolic traits in sub-Saharan Africa: A systematic review and meta-analysis. Int J Epidemiol. 2013;42(6):1754-1771. https://doi.org/10.1093/ije/dyt198

38. Agrawal A, Mital P, Goyal LK, Agarwal A, Nawal C, Kumar V. A study of risk factors and impact of HAART on blood pressure in North Indians living with HIV/AIDS. Sch AcadJBiosci.2015;3(1B):98-103.https://doi.org/10.2174/1874613601509010051

39. Kaplan RC, Kingsley LA, Sharrett AR, et al. Ten-year predicted coronary heart disease risk in HIV-infected men and women. Clin Infec Dis. 2007;45(8):1074-1081. https://doi.org/10.1086/521935

40. Pirro $M$, Mannarino MR, Francisci $D$, et al. Urinary albumin-to-creatinine ratio is associated with endothelial dysfunction in HIV-infected patients receivin antiretroviral therapy. Sci Rep. 2016;6:1-6. https://doi.org/10.1038/srep28741

41. Deckert T, Feldt-Rasmussen B, Borch-Johnsen K, Jensen T, Kofoed-Enevoldsen A. Albuminuria reflects widespread vascular damage. Diabetologia [serial online]. 1989 [cited 2017 Sep 13];32(4):219-226. Available from: https://www.ncbi.nlm. nih.gov/pubmed/2668076

42. Bruggeman LA, Nelson PJ. Controversies in the pathogenesis of HIV-associated renal diseases. Nat Rev Nephrol. 2009;5(10):574-581. https://doi.org/10.1038/ nrneph.2009.139

43. Valle R, Haragsim L. Nephrotoxicity as a complication of antiretroviral therapy. Adv Chronic Kidney Dis. 2006;13(3):314-319. https://doi.org/10.1038/nrneph.2009.139

44. Longenecker CT, Scherzer R, Bacchetti P, Lewis CE, Grunfeld C, Shlipak MG. HIV viremia and changes in kidney function. AIDS (London, England). 2009;23(9):1089-1096. https://doi.org/10.1097/QAD.0b013e32832a3f24

45. Kalayjian RC, Franceschini N, Gupta SK, et al. Suppression of HIV-1 replication by antiretroviral therapy improves renal function in persons with low CD4+ ce counts and chronic kidney disease. AIDS (London, England). 2008:22(4):481-487. https://doi.org/10.1097/QAD.0b013e3282f4706d

46. Gupta SK, Parker RA, Robbins GK, Dubé MP. The effects of highly active antiretroviral therapy on albuminuria in HIV-infected persons: Results from a randomized trial. Nephrol Dial Transplant. 2005;20(10):2237-2242. https://doi. org/10.1093/ndt/gfi053

47. Szczech LA, Menezes P, Byrd Quinlivan E, Van Der Horst C, Bartlett JA, Svetkey LP. Microalbuminuria predicts overt proteinuria among patients with HIV infection. HIVMed.2010;11(7):419-426.https://doi.org/10.1111/j.1468-1293.2009.00805.x

48. Brennan A, Evans D, Maskew M, et al. Relationship between renal dysfunction, nephrotoxicity and death among HIV adults on tenofovir. AIDS (London, England) 2011;25(13):1603-1609. https://doi.org/10.1097/QAD.0b013e32834957da 


\section{Appendix 1}

TABLE 1-A1: Characteristics of HIV-uninfected and HIV-infected individuals after adjusting for waist circumference.

\begin{tabular}{|c|c|c|c|}
\hline Variable & $\begin{array}{c}\text { HIV-uninfected } \\
N=\mathbf{1 1 4}\end{array}$ & $\begin{array}{c}\text { HIV-infected } \\
N=114\end{array}$ & $p$ \\
\hline \multicolumn{4}{|c|}{ Cardiovascular measurements } \\
\hline SBP, mmHg & $133 \pm 23.5$ & $127 \pm 23.5$ & 0.057 \\
\hline $\mathrm{DBP}, \mathrm{mmHg}$ & $87 \pm 13.2$ & $83 \pm 13.2$ & 0.029 \\
\hline $\mathrm{PP}, \mathrm{mmHg}$ & $46 \pm 14.6$ & $43 \pm 14.6$ & 0.278 \\
\hline MAP, mmHg & $102 \pm 15.9$ & $97 \pm 15.9$ & 0.032 \\
\hline cSBP, mmHg & $128 \pm 18.7$ & $121 \pm 18.9$ & 0.004 \\
\hline \multicolumn{4}{|l|}{ Biochemical variables } \\
\hline $\mathrm{TC}, \mathrm{mmol} / \mathrm{L}$ & $4.49 \pm 11.9$ & $4.56 \pm 11.9$ & 0.645 \\
\hline LDL-c, mmol/L & $2.72 \pm 16.4$ & $2.74 \pm 16.4$ & 0.911 \\
\hline $\mathrm{TG}, \mathrm{mmol} / \mathrm{L}$ & $1.12(1.02 ; 1.23)$ & $1.15(1.05 ; 1.27)$ & 0.642 \\
\hline $\mathrm{HDL}-\mathrm{c}, \mathrm{mmol} / \mathrm{L}$ & $1.29(1.21 ; 1.38)$ & $1.27(1.20 ; 1.36)$ & 0.731 \\
\hline TG/HDL-C ratio & $0.87(0.76 ; 0.98)$ & $1.10(0.80 ; 1.03)$ & 0.603 \\
\hline Glucose, $\mathrm{mmol} / \mathrm{L}$ & $5.23(5.01 ; 5.47)$ & $5.22(4.50 ; 5.43)$ & 0.937 \\
\hline $\mathrm{CRP}, \mathrm{mg} / \mathrm{L}$ & $0.99(0.67 ; 1.49)$ & $1.54(1.03 ; 2.30)$ & 0.146 \\
\hline \multicolumn{4}{|l|}{ Renal markers } \\
\hline $\mathrm{CrCl}, \mathrm{mL} / \mathrm{min}$ & $109(104 ; 114)$ & $105(100 ; 110)$ & 0.304 \\
\hline eGFR, $\mathrm{mL} / \mathrm{min} / 1.73 \mathrm{~m}^{2}$ & $102(101 ; 106)$ & $103(100 ; 105)$ & 0.573 \\
\hline $\mathrm{uACR}, \mathrm{mg} / \mathrm{mmol}$ & $1.50(1.21 ; 1.87)$ & $1.80(1.44 ; 2.24)$ & 0.270 \\
\hline
\end{tabular}

Data are adjusted means \pm SD or $-95 \%$ and $+95 \% \mathrm{Cl}$ for logarithmically transformed variables. SD, standard deviation; Cl, confidence interval; HIV, human immunodeficiency virus; $N$, number of participants; DBP, diastolic blood pressure; SBP, systolic blood pressure; PP, pulse pressure; MAP, mean arterial pressure; cSBP, central systolic blood pressure; TC, total cholesterol; LDL-cholesterol, low density lipoprotein cholesterol; HDL-cholesterol, high-density lipoprotein cholesterol; TG:HDL-C, triglycerides: High-density lipoprotein cholesterol; CRP, C-reactive protein; CrCl, creatinine clearance; eGFR, estimated glomerular filtration rate; UACR, urinary albumin-creatinine ratio.

TABLE 2-A1: Characteristics of the HIV-uninfected and HIV-infected individuals taking antiretroviral therapy.

\begin{tabular}{|c|c|c|c|}
\hline Variable & HIV-uninfected & $\begin{array}{l}\text { HIV-infected } \\
\text { taking ART }\end{array}$ & $p$ \\
\hline \multicolumn{4}{|l|}{ Men } \\
\hline$N$ & 23 & 17 & \multirow{2}{*}{0.975} \\
\hline$\%$ & 20.2 & 20.0 & \\
\hline Age, years & $53.4 \pm 5.5$ & $53.0 \pm 5.3$ & 0.636 \\
\hline \multicolumn{4}{|l|}{ Urban $N(\%)$} \\
\hline$N$ & 46 & 35 & \multirow{2}{*}{0.906} \\
\hline$\%$ & 40.4 & 41.2 & \\
\hline \multicolumn{4}{|l|}{ Anthropometry } \\
\hline WC & 91.6 & 82.6 & \multirow{2}{*}{$<0.001$} \\
\hline $\mathrm{cm}$ & $70.5 ; 123$ & $65.50 ; 109$ & \\
\hline BMI, & 27.4 & 23.0 & \multirow{2}{*}{$<0.001$} \\
\hline $\mathrm{kg} / \mathrm{m}^{2}$ & $18.0 ; 44.5$ & $15.6 ; 35.9$ & \\
\hline \multicolumn{4}{|c|}{ Cardiovascular measurements } \\
\hline $\mathrm{SBP}, \mathrm{mmHg}$ & $133 \pm 21$ & $125 \pm 23$ & 0.014 \\
\hline $\mathrm{DBP}, \mathrm{mmHg}$ & $88 \pm 12$ & $82 \pm 13$ & 0.001 \\
\hline $\mathrm{PP}, \mathrm{mmHg}$ & $45 \pm 14$ & $43 \pm 15$ & 0.308 \\
\hline $\mathrm{MAP}, \mathrm{mmHg}$ & $103 \pm 14$ & $97 \pm 15$ & 0.003 \\
\hline cSBP, mmHg & $129 \pm 18$ & $118 \pm 16$ & $<0.001$ \\
\hline \multicolumn{4}{|c|}{ Biochemical variables } \\
\hline $\mathrm{TC}, \mathrm{mmol} / \mathrm{L}$ & $4.54 \pm 1.16$ & $4.50 \pm 0.92$ & 0.794 \\
\hline LDL-c, mmol/L & $2.79 \pm 1.02$ & $2.61 \pm 0.87$ & 0.201 \\
\hline TG & 1.18 & 1.14 & \multirow{2}{*}{0.689} \\
\hline $\mathrm{mmol} / \mathrm{L}$ & $0.53 ; 2.85$ & $0.54 ; 2.35$ & \\
\hline HDL-c & 1.25 & 1.34 & \multirow{2}{*}{0.148} \\
\hline $\mathrm{mmol} / \mathrm{L}$ & $0.69 ; 2.27$ & $0.79 ; 2.53$ & \\
\hline Glucose, $\mathrm{mmol} / \mathrm{L}$ & 5.34 & 5.15 & \multirow{2}{*}{0.491} \\
\hline $\mathrm{mmol} / \mathrm{L}$ & $3.85 ; 9.03$ & $4.26 ; 6.10$ & \\
\hline HbA1c & 5.92 & 5.41 & \multirow{2}{*}{$<0.001$} \\
\hline$\%$ & $5.00 ; 8.80$ & $4.90 ; 6.20$ & \\
\hline
\end{tabular}

TABLE 2-A1 (Continues...): Characteristics of the HIV-uninfected and HIV-infected individuals taking antiretroviral therapy.

\begin{tabular}{|c|c|c|c|}
\hline Variable & HIV-uninfected & $\begin{array}{l}\text { HIV-infected } \\
\text { taking ART }\end{array}$ & $p$ \\
\hline CRP & 1.11 & 1.71 & \multirow{2}{*}{0.160} \\
\hline $\mathrm{mg} / \mathrm{L}$ & $0.05 ; 16.1$ & $0.04 ; 44.7$ & \\
\hline$\gamma$-glutamyltransferase & 23.2 & 26.7 & \multirow{2}{*}{0.538} \\
\hline$U / L$ & $1.46 ; 256$ & $1.24 ; 225$ & \\
\hline \multicolumn{4}{|l|}{ HIV-related parameters } \\
\hline $\mathrm{CD} 4+$ cell count, cell $/ \mathrm{mm}^{3}$ & - & $525 \pm 264$ & - \\
\hline$\leq 500$ cells $/ \mathrm{mm}^{3}$ & - & & - \\
\hline$N$ & - & $37 / 78$ & - \\
\hline$\%$ & - & 47.4 & - \\
\hline$\leq 200$ cells $/ \mathrm{mm}^{3}$ & - & - & - \\
\hline$N$ & - & $7 / 78$ & - \\
\hline$\%$ & - & 8.97 & - \\
\hline \multicolumn{4}{|l|}{ Renal function } \\
\hline $\mathrm{Scr}, \mu \mathrm{mol} / \mathrm{L}$ & $55.9 \pm 11.4$ & $56.4 \pm 12.6$ & 0.787 \\
\hline $\mathrm{CrCl}$ & 116 & 100 & \multirow{2}{*}{0.002} \\
\hline $\mathrm{mL} / \mathrm{min}$ & $72.0 ; 207$ & $56.0 ; 167$ & \\
\hline \multicolumn{4}{|l|}{$\mathrm{CrCl},<50 \mathrm{~mL} / \mathrm{min}$} \\
\hline$N$ & $0 / 113$ & $1 / 84$ & \multirow[t]{2}{*}{0.245} \\
\hline$\%$ & 0.00 & 1.09 & \\
\hline eGFR, & 103 & 102 & \multirow{2}{*}{0.504} \\
\hline $\mathrm{mL} / \mathrm{min} / 1.73 \mathrm{~m}^{2}$ & $83.2 ; 123$ & $79.2 ; 120$ & \\
\hline \multicolumn{4}{|c|}{ eGFR, $<90 \mathrm{~mL} / \mathrm{min} / 1.73 \mathrm{~m}^{2}, N(\%)$} \\
\hline$N$ & 14 & 8 & \multirow[t]{2}{*}{0.523} \\
\hline$\%$ & 12.3 & 9.41 & \\
\hline UACR & 1.43 & 1.89 & \multirow{2}{*}{0.109} \\
\hline $\mathrm{mg} / \mathrm{mmol}$ & $0.43 ; 14.6$ & $0.48 ; 22.6$ & \\
\hline \multicolumn{4}{|c|}{$\mathrm{uACR}, 3 \mathrm{mg} / \mathrm{mmol}-30 \mathrm{mg} / \mathrm{mmol}, \mathrm{N}(\%)$} \\
\hline$N$ & $18 / 102$ & $19 / 76$ & \multirow[t]{2}{*}{0.232} \\
\hline$\%$ & 17.7 & 25.0 & \\
\hline
\end{tabular}


TABLE 2-A1 (Continues...): Characteristics of the HIV-uninfected and HIV-infected individuals taking antiretroviral therapy.

\begin{tabular}{|c|c|c|c|}
\hline Variable & HIV-uninfected & $\begin{array}{l}\text { HIV-infected } \\
\text { taking ART }\end{array}$ & $p$ \\
\hline \multicolumn{4}{|c|}{ Health behaviours } \\
\hline \multicolumn{4}{|c|}{ Self-reported alcohol use, $N(\%)$} \\
\hline$N$ & $34 / 113$ & $25 / 84$ & 0.961 \\
\hline$\%$ & 30.1 & 29.8 & \\
\hline \multicolumn{4}{|c|}{ Self-reported tobacco use, $N(\%)$} \\
\hline$N$ & $41 / 113$ & $33 / 84$ & 0.667 \\
\hline$\%$ & 36.3 & 39.3 & \\
\hline \multicolumn{4}{|c|}{ Medication use } \\
\hline \multicolumn{4}{|c|}{ Antihypertensives } \\
\hline$N$ & 35 & 11 & 0.003 \\
\hline$\%$ & 30.7 & 12.9 & \\
\hline \multicolumn{4}{|l|}{ Diuretics } \\
\hline$N$ & 38 & 16 & 0.023 \\
\hline$\%$ & 33.3 & 18.8 & \\
\hline \multicolumn{4}{|l|}{ Statins } \\
\hline$N$ & 6 & 1 & 0.122 \\
\hline$\%$ & 5.3 & 1.2 & \\
\hline \multicolumn{4}{|c|}{ Anti-inflammatories } \\
\hline$N$ & 8 & 6 & 0.991 \\
\hline$\%$ & 7.0 & 7.1 & \\
\hline
\end{tabular}

TABLE 2-A1 (Continues...): Characteristics of the HIV-uninfected and HIV-infected individuals taking antiretroviral therapy.

\begin{tabular}{lccc}
\hline Variable & HIV-uninfected & $\begin{array}{c}\text { HIV-infected } \\
\text { taking ART }\end{array}$ & $\boldsymbol{p}$ \\
\hline Antidiabetic agents & 10 & 0 & 0.005 \\
$\quad N$ & 8.8 & 0.0 & \\
$\%$ & & & \\
Anticoagulants & 9 & 3 & 0.200 \\
$N$ & 7.9 & 3.5 & \\
$\%$ & & & \\
$\geq 5$ years on ART & - & $38 / 59$ & - \\
$N$ & - & 64.4 & \\
$\%$ & & & \\
Metabolic syndrome & 50 & 24 & 0.024 \\
$N$ & 43.9 & 24.2 & \\
$\%$ & & & \\
\hline
\end{tabular}

Data are arithmetic mean \pm s.d. or geometric mean (5th and 95 th percentile intervals) for logarithmically transformed variables.

HIV-uninfected, $N=114$; HIV-infected taking ART, $N=85$.

s.d., standard deviation; $\mathrm{Cl}$, confidence interval; HIV, human immunodeficiency virus; $N$ number of participants; WC, waist circumference; BMI, body mass index; DBP, diastoli blood pressure; SBP, systolic blood pressure; PP, pulse pressure; MAP, mean arterial pressure; CSBP, central systolic blood pressure; TC, total cholesterol; LDL-cholesterol, low density lipoprotein cholesterol; HDL-cholesterol, high-density lipoprotein cholesterol; CRP, C-reactive protein; $\mathrm{SCr}$, serum creatinine; $\mathrm{CrCl}$, creatinine clearance; eGFR, estimated glomerular filtration rate; $\mathrm{UACR}$, urinary albumin-creatinine ratio; Med, medication; ART, antiretroviral therapy; $N$, number

TABLE 3-A1: Multiple regression analysis with markers of renal function as dependent variables, after excluding individuals not using ART.

\begin{tabular}{|c|c|c|c|c|c|c|c|c|c|}
\hline \multirow[t]{2}{*}{ Variable } & \multicolumn{3}{|c|}{$\mathrm{CrCl}, \mathrm{mL} / \mathrm{min}$} & \multicolumn{3}{|c|}{ eGFR, $\mathrm{mL} / \mathrm{min} / 1.72 \mathrm{~m}^{2}$} & \multicolumn{3}{|c|}{ uACR, $\mathrm{mg} / \mathrm{mmol}$} \\
\hline & $\beta$ & $95 \% \mathrm{Cl}$ & $p$ & $\beta$ & $95 \% \mathrm{Cl}$ & $p$ & $\beta$ & $95 \% \mathrm{Cl}$ & $p$ \\
\hline Age, years & -0.2 & $-0.39 ; 0.58$ & 0.010 & -0.5 & $-0.87 ; 1.09$ & $<0.001$ & -0.1 & $0.01 ; 0.22$ & 0.594 \\
\hline Sex, women, men & -0 & $0.08 ; 0.11$ & 0.924 & 0.24 & $-0.37 ;-0.26$ & 0.027 & -0.1 & $-0.11 ; 0.33$ & 0.302 \\
\hline cSBP, $\mathrm{mmHg}$ & 0.1 & $-0.09 ; 0.31$ & 0.337 & 0.07 & $-0.01 ; 0.25$ & 0.568 & 0.37 & $-0.61 ; 0.85$ & 0.003 \\
\hline WC, $\mathrm{cm}$ & 0.5 & $-0.8 ; 1.10$ & $<0.001$ & -0.1 & $-0.07 ; 0.35$ & 0.45 & -0.3 & $-0.38 ; 0.67$ & 0.064 \\
\hline HDL-C, $\mathrm{mmol} / \mathrm{L}$ & -0 & $0.05 ; 0.17$ & 0.768 & 0.04 & $0.04 ; 0.20$ & 0.739 & -0 & $0.08 ; 0.16$ & 0.875 \\
\hline TG mmol/L & -0.3 & $-0.38 ; 0.60$ & 0.028 & -0.1 & $-0.05 ; 0.31$ & 0.461 & 0.9 & $-0.05 ; 0.30$ & 0.479 \\
\hline $\mathrm{HbA1c}, \%$ & 0.02 & $0.07 ; 0.14$ & 0.849 & -0.1 & $-0.06 ; 0.30$ & 0.432 & -0.3 & $-0.40 ; 0.64$ & 0.872 \\
\hline $\mathrm{CRP}, \mathrm{mg} / \mathrm{L}$ & 0.1 & $-0.09 ; 0.28$ & 0.329 & -0 & $0.06 ; 0.15$ & 0.835 & -0.2 & $-0.22 ; 0.44$ & 0.127 \\
\hline MetS, no/yes & 0.05 & $0.03 ; 0.23$ & 0.690 & 0.21 & $-0.10 ; 0.39$ & 0.148 & 0.36 & $-0.56 ; 0.86$ & 0.017 \\
\hline CD4+ count, $\mathrm{mm}^{3}$ & 0.25 & $-0.40 ; 0.59$ & 0.009 & 0.19 & $-0.26 ; 0.47$ & 0.079 & -0.2 & $-0.23 ; 0.45$ & 0.112 \\
\hline
\end{tabular}

$\mathrm{CrCl}, \mathrm{mL} / \mathrm{min}, R^{2}=0.533 ; \mathrm{eGFR}, \mathrm{mL} / \mathrm{min} / 1.72 \mathrm{~m}^{2}, R^{2}=0.227 ; \mathrm{uACR}, \mathrm{mg} / \mathrm{mmol}, R^{2}=0.202$.

HIV-infected group using ART $(N=85)$.

$\beta$, partial regression coefficient; $R^{2}$, adjusted $R^{2} ; 95 \% \mathrm{Cl}, 95 \%$ confidence interval of $\beta$; HIV, human immunodeficiency syndrome; eGFR, estimated glomerular filtration rate; uACR, urinaryalbumin creatinine ratio; $\mathrm{CrCl}$, creatinine clearance; cSBP, central systolic blood pressure; WC, waist circumference; HDL-C, high-density lipoprotein cholesterol; TG, triglycerides; HbA1c\%, glycosylated haemoglobin; CRP, C-reactive protein; MetS, metabolic syndrome. eGFR, UACR, CrCl, CSBP, WC, HDL-C, TG and CRP were logarithmically transformed. Bold values indicate $p \leq 0.05$. 